Article

\title{
Impact of Express Delivery Industry's Development on Transportation Sector's Carbon Emissions: An Empirical Analysis from China
}

\author{
Chang Zhao ${ }^{1}$ and Boya Zhou ${ }^{2, *}$ \\ 1 College of Public Administration, Huazhong University of Science and Technology, Wuhan 430074, China; \\ zhaochang@hust.edu.cn \\ 2 School of Public Administration, Zhongnan University of Economics and Law, Wuhan 430073, China \\ * Correspondence: zhouboya@zuel.edu.cn
}

\section{check for} updates

Citation: Zhao, C.; Zhou, B. Impact of Express Delivery Industry's Development on Transportation Sector's Carbon Emissions: An Empirical Analysis from China. Sustainability 2021, 13, 8908. https:/ / doi.org/10.3390/su13168908

Academic Editors:

Andres Muñoz-Villamizar,

Jairo Montoya-Torres and

Christopher Mejía Argueta

Received: 11 June 2021

Accepted: 3 August 2021

Published: 9 August 2021

Publisher's Note: MDPI stays neutral with regard to jurisdictional claims in published maps and institutional affiliations.

Copyright: (c) 2021 by the authors. Licensee MDPI, Basel, Switzerland. This article is an open access article distributed under the terms and conditions of the Creative Commons Attribution (CC BY) license (https:// creativecommons.org/licenses/by/ $4.0 /)$.

\begin{abstract}
In recent years, China's express delivery industry has developed rapidly. According to a rough estimate in this paper, carbon emissions caused by express parcel transportation in China account for $1 / 7$ of the transportation sector's carbon emissions. However, considering the possibility of a scale effect, it is unclear whether the express delivery industry's development will inevitably lead to more carbon emissions. Therefore, this paper uses the panel data of 30 Chinese provinces from 2008 to 2017 to explore the complex relationship between the express delivery industry's development and the transportation sector's carbon emissions, and also conducts regional heterogeneity analysis. The main findings are as follows: (1) There is a significant U-shaped relationship between per capita express delivery amounts and the transportation sector's $\mathrm{CO}_{2}$ emissions, especially in the Central region. (2) At the national level, the number of per capita postal outlets significantly promotes the transportation sector's $\mathrm{CO}_{2}$ emissions. (3) The impact caused by the number of per capita postal workers varies regionally. Increasing postal worker numbers in the Western region can significantly reduce carbon emissions, while the result in the Central region is the opposite. (4) The Express Comprehensive Development Index (ECDI) has a significant U-shaped effect on the transportation sector's carbon emissions at the national and sub-regional level.
\end{abstract}

Keywords: express delivery industry; transportation sector; $\mathrm{CO}_{2}$ emissions; panel data regression model; sub-regional analysis

\section{Introduction}

In recent years, the development of e-commerce in China has greatly stimulated the online shopping consumption of residents [1], which provides new growth space for the development of the express delivery industry [2,3]. Since 2014, the express delivery volume in China has ranked first in the world for six consecutive years. The logistics and express delivery industries have an important strategic position in the national economy and in people's livelihoods. Especially during the COVID-19 epidemic in 2020, the logistics and express delivery industries provided a strong guarantee for the timely transportation of antiepidemic relief supplies and household goods (e.g., daily necessities, fresh foods, medicines, learning materials). Meanwhile, isolation at home has generated more demand for online shopping, thus promoting the express delivery industry's development. Data show that China's express delivery amount reached 47.77 billion pieces in the first eight months of 2020 [4], which relies heavily on the strong support of express parcel transportation.

At the same time, environmental problems caused by the express delivery industry have gradually attracted widespread attention. China's express parcel transportation mainly relies on diesel vehicles. Compared to small cars and electric cars used by urban households, diesel vehicles will consume more fossil energy and generate huge carbon 
emissions during driving [5], which inevitably makes the express delivery industry contribute to the carbon emissions of the transportation sector $[6,7]$. According to previous literature, this study preliminarily estimates that the direct carbon emissions caused by the development of China's express delivery industry has exceeded $1 / 7$ of the entire transportation sector and may continue to rise, which will bring a heavy burden on China's emission reduction efforts [8-10]. In order to mitigate climate change and achieve a winwin situation between economic development and environmental protection, determining how to reduce the carbon emissions caused by the express delivery industry has become an important issue in the practice of sustainable development in China.

The existing research on the environmental problems caused by the express delivery industry mainly focuses on express packaging waste. However, there are few researches discussing the carbon emissions caused by the express delivery industry from a comprehensive and quantitative perspective. Only a few qualitative studies mention that the explosive growth of the express delivery industry will increase carbon emissions. In addition, as far as we know, there is currently no literature that focuses on the different effects caused by the specific indicators of the express delivery industry's development (i.e., per capita express delivery amount, number of per capita postal outlets and per capita postal workers). In order to fill the research gap, this paper uses provincial panel data and econometric models containing quadratic terms to explore the possible nonlinear relationship between the express delivery industry's development and the transportation sector's carbon emissions. Meanwhile, we also conducted a sub-regional regression to discuss regional heterogeneity.

The remaining part of this paper is organized as follows: Section 2 reviews the literature about the impact of the express delivery industry on carbon emissions. Section 3 introduces the selection of variables, main hypothesis, data sources and model construction. Section 4 presents the empirical results of nationwide and sub-regional regressions. Section 5 summarizes and discusses the research conclusions.

\section{Literature Review}

The developed countries have made a long-term exploration in the field of low-carbon transportation, which is helpful to deal with the carbon emission problem caused by the development of the express delivery industry. In fact, some developed countries have already started to use new energy vehicles with near-zero emissions [11-13]. For example, the German logistics company DHL has launched a carbon-neutral transportation service in the Asia Pacific Region, "DHL GOGREEN EXPRESS", reducing and offsetting carbon emissions in parcel transportation through the reinvestment of carbon management projects (e.g., fuel vehicles technology, solar panels, and re-forestation) [14]. However, the situation in developing countries is less optimistic. For example, due to the lack of specific carbon emission reduction goals, the implementation of low-carbon transportation policies formulated by the Russian and Pakistani governments is not satisfactory or even smoothly implemented [15,16].

As the world's second largest economy, China's express delivery demand will continue to rise. Since 2013, China has become the most influential international electronics market and has large-scale online sales [17], which has provided impetus for the explosive development of the express delivery industry [18]. Data show that the parcel transportation amount of China was 3.9 times that of the United States and 5.6 times that of Japan in 2018 [19]. Figure 1 visually shows the growth trend of China's express delivery amounts from 2007-2019. In this context, the number of express delivery companies has grown rapidly [20]. In order to gain more market share, improve market competitiveness, and establish an express delivery services network in the short term, express delivery companies usually choose to increase investment in postal outlets, postal workers, and transportation vehicles [21]. However, China's new energy technologies are not mature enough. Taking into account recharge mileage, fast charging infrastructure, charging time, safety and reliability, battery price, current and future fuel costs, and battery recycling [22-24], most express delivery companies prefer to use heavy diesel vehicles rather than fuel cell vehicles. 
Therefore, despite the many efforts that have been made, local governments still face many difficulties in formulating and implementing policies and measures to reduce emissions.

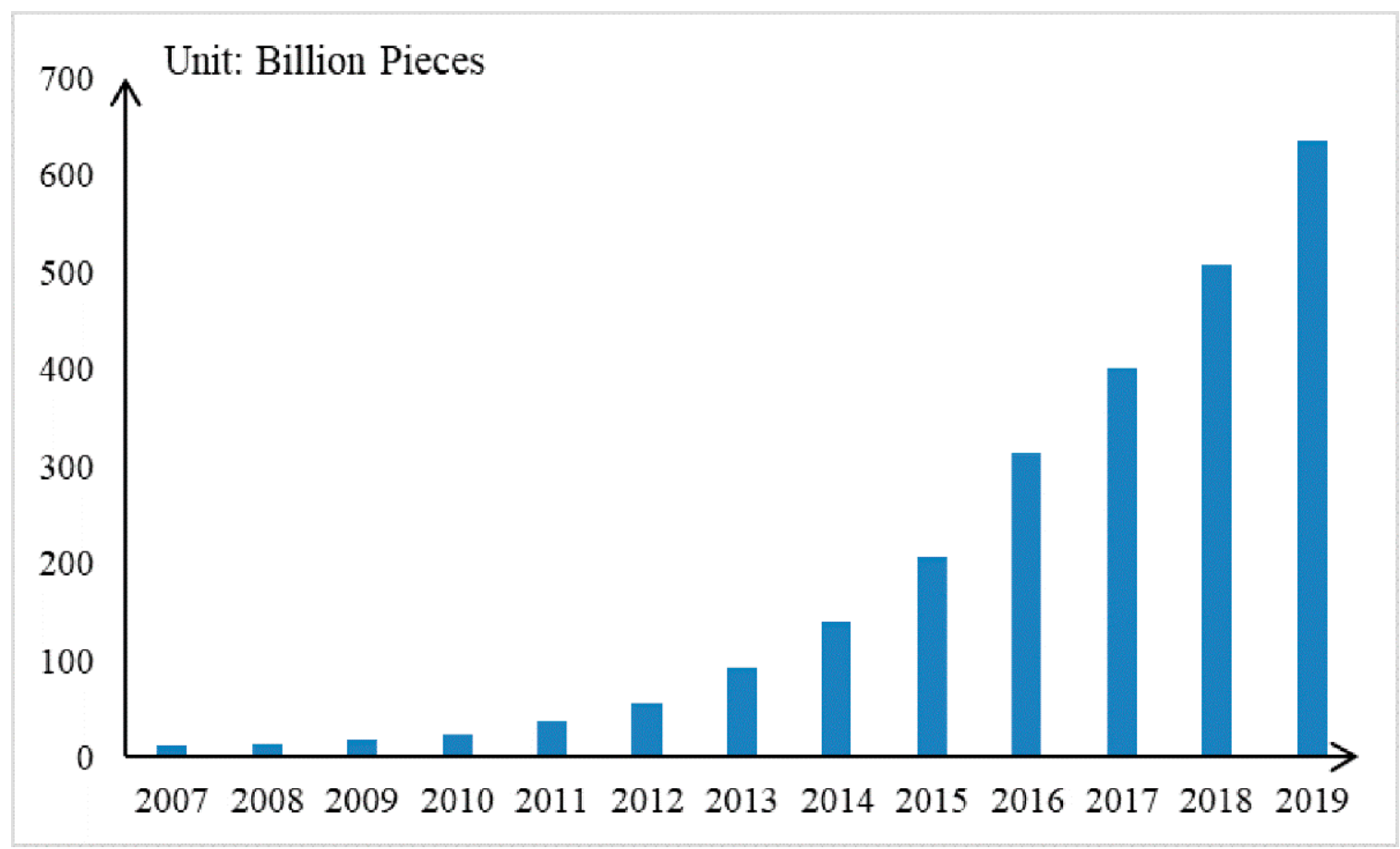

Figure 1. Trends of China's express delivery amount from 2000 to 2020.

Based on this, the emission problem caused by express parcel transportation has gradually aroused the research interest of scholars. Weideli [25] used the Monte Carlo method to simulate the carbon footprint of consumers in different shopping processes. He pointed out that in many scenarios, online shopping is more environmentally friendly than traditional brick-and-mortar store shopping. A study by the University of California on online shopping showed that fast shipping creates a heavier carbon footprint than its slower counterpart [26]. Stolaroff et al. [27] also found that the greenhouse gas emissions of small express drones are lower than ground transportation.

The influencing factors and specific characteristics of carbon emissions from urban freight transport have also attracted many scholars' attention. Steenhof et al. [28] used decomposition techniques and scenario exploration to point out that cross-border trade and the widespread application of heavy diesel vehicles are important factors for increasing carbon emissions in the transportation field. Kang et al. [8] quantified the impact of intracity express delivery services on emissions by using a spatial dynamic model. He found that express delivery amounts and their associated carbon emissions have significant spatial clustering properties, and the carbon emission intensity of the express delivery industry has a close correlation with the socio-economic status of the city. Jin et al. [29] discussed the impact of policy parameters on the carbon emissions and logistics costs of the supply chain of Wal-Mart (a large US retailer) and suggested that the appropriate transportation mode should be selected according to the carbon policy. Other scholars have also explored the emission effects of different road options in express parcel transportation. They argued that providing multiple routes, using new energy vehicles, and matching vehicle type to the terrain and road conditions of a transportation area could achieve additional emission reduction [30,31].

In summary, the existing literature mainly focuses on the environmental impacts caused by the transportation system in a specific geographic scope or a specific logistics process [32-34], but there is a lack of research on the actual emission effects of the express delivery industry. In fact, although it is difficult to measure the direct carbon emissions 
caused by the express delivery industry's development, the methods for measuring the transportation sector's carbon emissions are quite mature. Therefore, based on a scientific calculation of the transportation sector's carbon emissions, this study attempts to explore the actual impact of three major indicators of the express delivery industry's development on the transportation sector's $\mathrm{CO}_{2}$ emissions in China. This will provide empirical evidence and data support for governments and companies to formulate low-carbon development strategies for the express delivery industry.

\section{Variable Selection, Data Sources, and Model Construction}

In this section, the paper will specifically introduce variables, data sources, and models involved in the research.

\subsection{Variable Selection}

According to the development status and operating mode of China's express delivery industry, this paper simplifies the process of express parcel transportation into two stages [21]. The first stage is the long-distance transportation from sellers' warehouses to each postal outlet, mainly relying on highway transportation and diesel vehicles. This stage will generate a large amount of carbon emissions [28]. The second stage is the short-distance transportation from postal outlets to consignees, and mainly uses electric vehicles (e.g., electric motorcycles, electric tricycles, and electric trucks), which helps to reduce energy consumption and carbon emissions from express parcel transportation [35]. Figure 2 shows the flow chart of express parcel transportation.

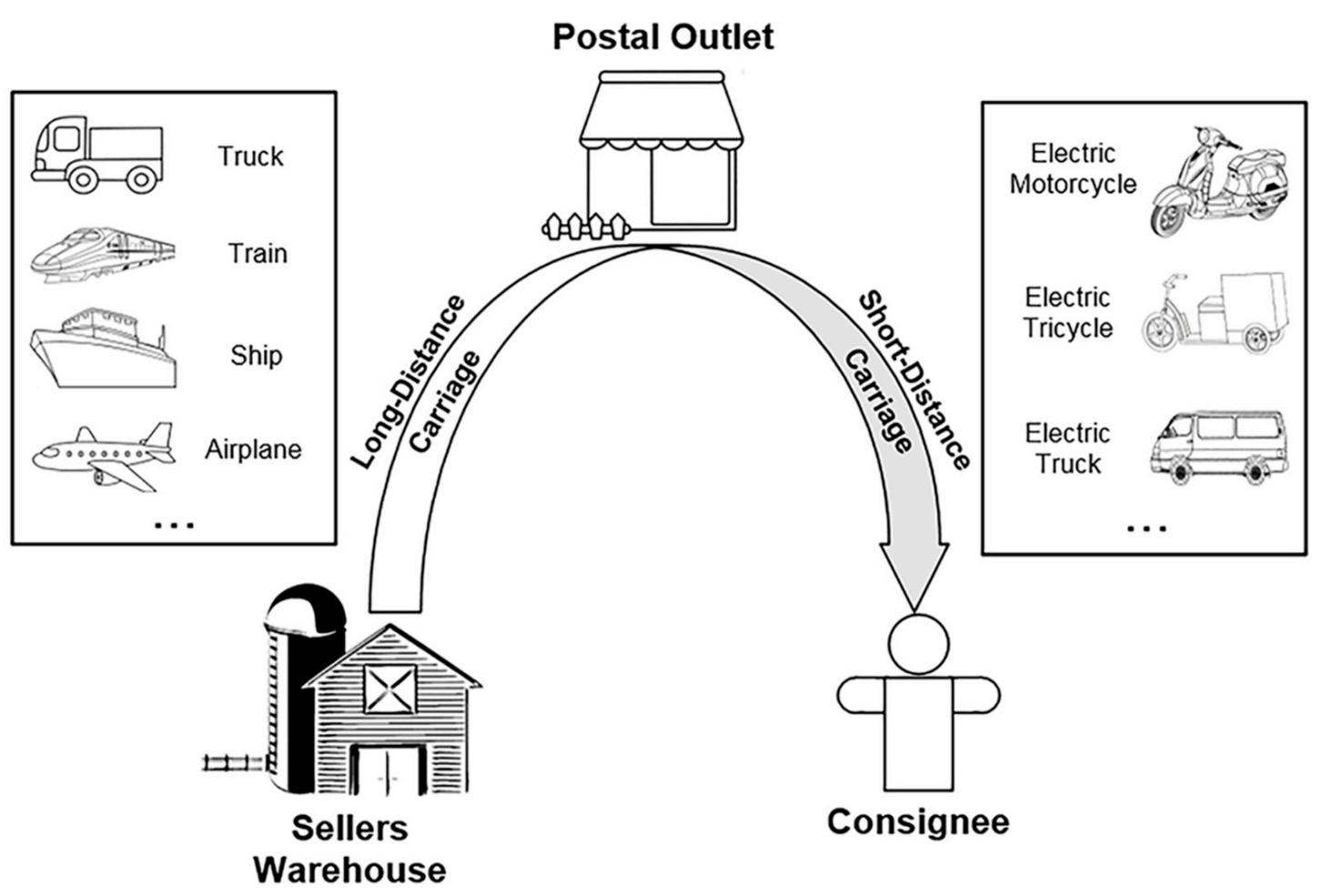

Figure 2. Express parcel transportation flow chart.

The dependent variable of this study is the per capita $\mathrm{CO}_{2}$ emissions of the transportation sector. The independent variables of this study are the per capita express delivery amount, the number of per capita postal outlets, and the number of per capita postal workers. As important components of the express delivery industry's development, the above three indicators are mainly used to measure the development status of the regional express delivery industry. In addition, in order to ensure the accuracy of regression results, the regression model of this study also includes five control variables. 


\subsubsection{Dependent Variable}

In order to control and reduce the influence of demographic factors, the dependent variable of this study is defined by the ratio of total $\mathrm{CO}_{2}$ emissions of transportation sector in each provincial administrative unit to total population of the region. Since there are no official statistics, this paper calculates the $\mathrm{CO}_{2}$ emissions of provincial transportation sectors according to methods developed by the Intergovernmental Panel on Climate Change [36]. The specific calculation formula of the "top-down" method used in this paper is as follows [37]:

$$
\mathrm{CO}_{2} \text { emissions }=\sum \varphi_{i} \times \xi_{i} \times \text { energy } y_{i}
$$

$\varphi_{i}$ is standard coal coefficient of the $i$ th energy source, $\xi_{i}$ is corresponding $\mathrm{CO}_{2}$ emissions coefficient of the $i$ th energy source, and energy $y_{i}$ is the consumption amount of the ith energy source.

Considering the actual situation of the express industry, this paper only discusses the emissions of the four major transportation modes of highway, aviation, railway, and waterway [38]. The corresponding transportation tools and energy types are trucks (diesel), automobiles (gasoline), airplanes (kerosene), trains (diesel), and ships (fuel oil). Based on the standard coal conversion coefficients of the above four energy sources (see Table 1), the $\mathrm{CO}_{2}$ emission coefficients [39,40], and Equation (1), we calculate the $\mathrm{CO}_{2}$ emissions of the transportation sector in 30 provincial administrative units in mainland China from 2008 to 2017. Meanwhile, Figure 3 describes the spatial distribution of regional $\mathrm{CO}_{2}$ emissions in 2008, 2011, 2014, and 2017. Due to a lack of data, this study does not include Tibet.

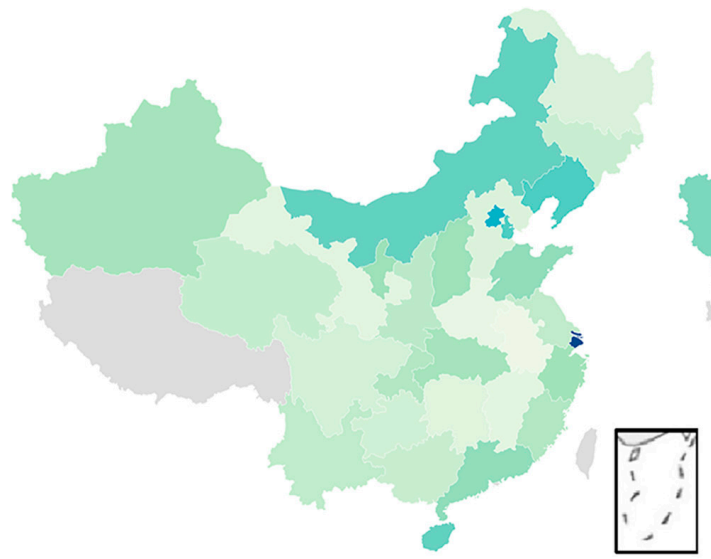

2008

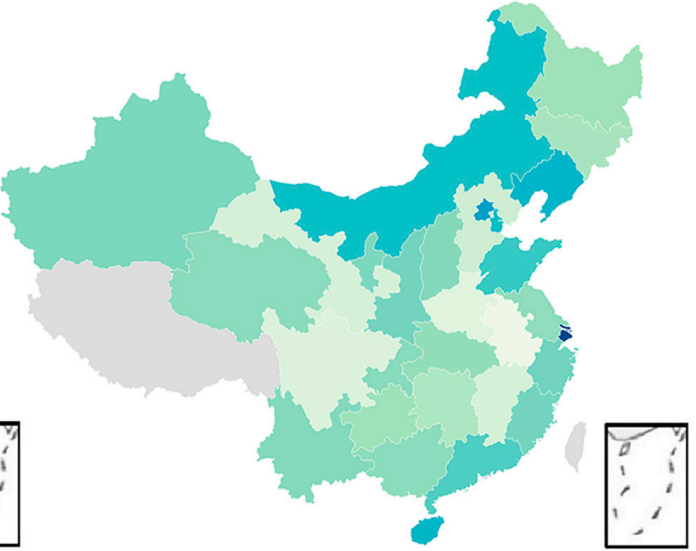

2011

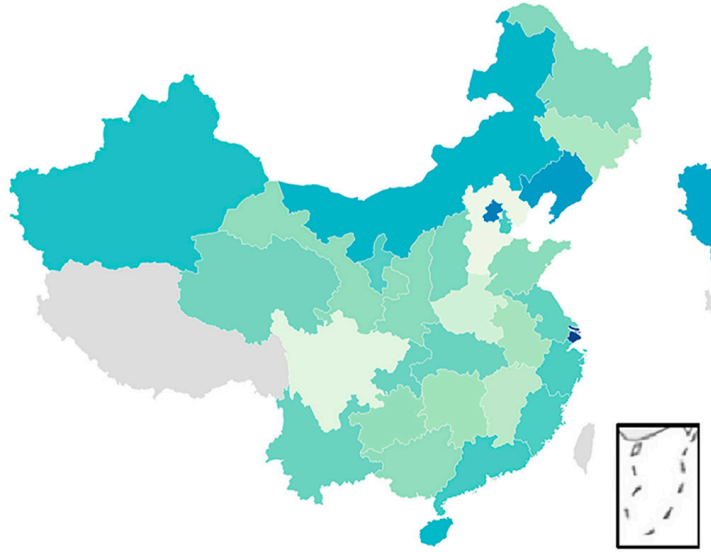

2014

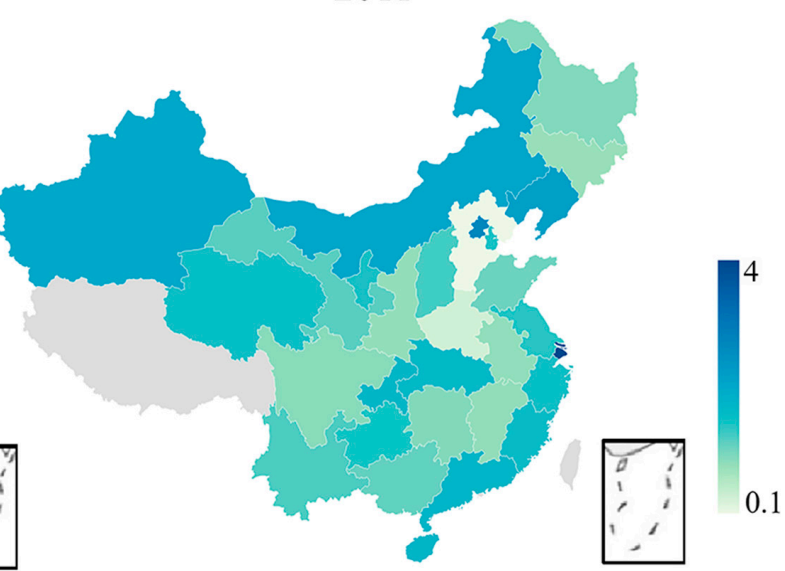

2017

Figure 3. Spatial distribution maps of the per capita $\mathrm{CO}_{2}$ emissions of the transportation sector. The gray part in the map is Tibet, which is not included in the scope of this study. Note: The map of China comes from public sources. 
Table 1. Standard coal coefficients and $\mathrm{CO}_{2}$ emission coefficients.

\begin{tabular}{|c|c|c|c|c|}
\hline & Diesel (kg) & Gasoline (kg) & Kerosene (kg) & Fuel Oil (kg) \\
\hline $\begin{array}{c}\text { Standard coal } \\
\text { conversion coefficient } \\
(\mathrm{kg} \text { standard coal } / \mathrm{kg}, \\
\mathrm{kg} \text { standard coal } / \mathrm{kW} \cdot \mathrm{h})\end{array}$ & 1.4571 & 1.4714 & 1.4714 & 1.4286 \\
\hline
\end{tabular}

\subsubsection{Independent Variables}

Firstly, this study uses the per capita express delivery amount, number of per capita postal outlets, and number of per capita postal workers to discuss the impact of the express delivery industry's development on the transportation sector's $\mathrm{CO}_{2}$ emissions from a macro perspective.

\section{Per capita Express Delivery Amount}

The per capita express delivery amount refers to the per capita number of express parcels delivered in a certain region. The express delivery amount can reflect the transportation frequency between different regions to a certain extent. More express delivery across cities and regions means there is a higher transportation frequency of express parcels. In different development stages of the express delivery industry, the impact of the per capita express delivery amount on the transportation sector's $\mathrm{CO}_{2}$ emissions may also be different. For ease of analysis, this paper simplifies the current development status of the Chinese express delivery industry into two stages of initial development and rapid development. In the early development stage of the express delivery industry, due to convenience and high-cost performance, online shopping shows a clear substitution effect on private shopping [41]. As the frequency and mileage of private cars decreases, the energy consumption and carbon emissions generated by residents' travel reduces [42] In addition, the scale effect brought by the centralized transportation of express parcels may also help to reduce carbon emissions. However, with the rapid development of the express delivery industry, the number of parcels has shown an explosive growth trend. High-frequency express parcel transportation has greatly increased the demand for fossil energy, which inevitably weakened the carbon reduction effect of the scale effect [43]. That is, the consumption of a large amount of fossil energy will further increase the carbon emissions of the transportation sector. Therefore, this paper predicts that with an increase in the per capita express delivery amount, the transportation sector's $\mathrm{CO}_{2}$ emissions will first decrease and then increase; namely, there may be an inflection point. This logic often appears in economics and environmental quality research (e.g., Environmental Kuznets Curve, EKC) [44-47]. Therefore, based on the above discussion, we can assume that there is a U-shaped relationship between the per capita express delivery amount and the transportation sector's carbon emissions, which is the first Hypothesis (H1) of this study.

Hypothesis 1 (H1). There is a U-shaped relationship between the per capita express delivery amount and the transportation sector's $\mathrm{CO}_{2}$ emissions.

\section{Number of Per Capita Postal Outlets}

Postal outlets are important nodes connecting sellers and consumers, mainly providing customers with the terminal collection, storage, and distribution services of express parcels. The number and layout of postal outlets are not only related to the frequency, path, time, and distance of long-distance transportation of vehicles, but also affect the scope of shortdistance distribution [48]. The increase in the number of postal outlets means that the transportation time and distance from sellers' warehouses to postal outlets will increase, which will lead to more energy consumption and carbon emissions in the transportation sector. Therefore, this paper proposes the second hypothesis (H2). 
Hypothesis 2 (H2). The impact of the number of per capita postal outlets on the transportation sector's $\mathrm{CO}_{2}$ emissions is positive.

\section{Number of Per Capita Postal Workers}

Postal workers mainly use electric vehicles to receive and distribute express parcels, which has a huge potential to reduce energy consumption and carbon emissions compared to traditional fuel vehicles [49]. At the same time, more and more well-educated people are joining the express delivery industry. Due to their higher environmental awareness, they are more willing to use clean energy and engage in low-carbon behaviors, thus helping to reduce carbon emissions from express parcel transportation [50]. Based on the above two factors, this paper argues that increasing the number of postal workers plays a positive role in reducing the transportation sector's carbon emissions. Therefore, the third hypothesis (H3) of this paper is as follows.

Hypothesis 3 (H3). The impact of the number of per capita postal workers on the transportation sector's $\mathrm{CO}_{2}$ emissions is negative.

Figure 4 shows the change tendencies of the per capita express delivery amount, number of per capita postal outlets, and per capita postal workers in China from 2008 to 2017, respectively. Overall, these three indicators developed unevenly in different regions. The express delivery industry in the Eastern region developed rapidly, while that in the Central and Western regions developed relatively backward.
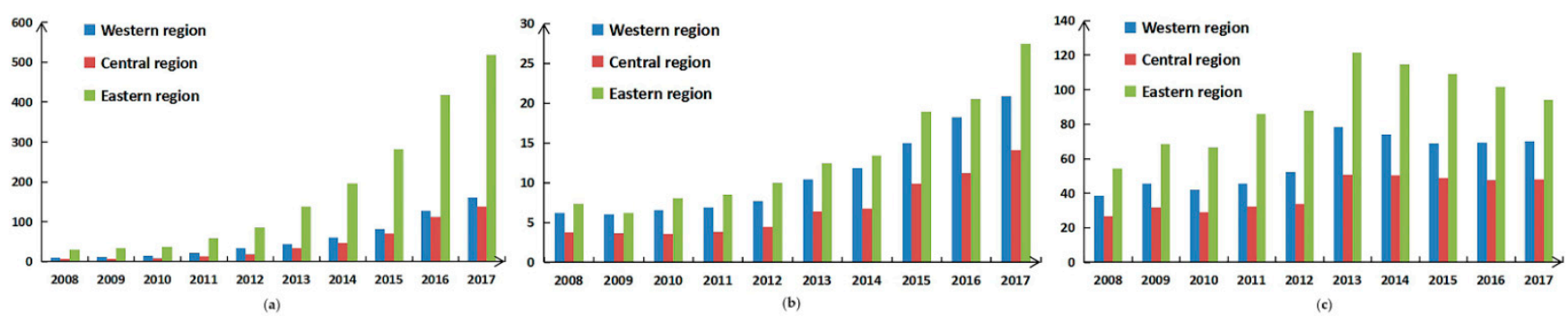

Figure 4. (a) Trend of per capita express delivery amount from 2008 to 2017; (b) trend of the number of per capita postal outlets from 2008 to 2017; (c) trend of the number of per capita postal workers from 2008 to 2017.

\section{Express Comprehensive Development Index (ECDI)}

Based on the above statements, this study further analyzes the relationship between the development level of the express delivery industry and carbon emissions. Due to the lack of direct official data, this study uses the three major indicators of the express delivery industry's development and entropy method to calculate the Express Comprehensive Development Index (ECDI), objectively measuring the development level of the express delivery industry in each province [51]. Among them, the weights of the per capita express delivery amount, number of per capita postal outlets, and number of per capita postal workers are $0.51,0.24$, and 0.25 , respectively (see Appendix A for specific calculation steps).

Next, we analyze the possible relationship between ECDI and the transportation sector's $\mathrm{CO}_{2}$ emissions from a realistic and technical perspective. From a realistic point of view, in the early development of the express delivery industry, the transportation and distribution services provided by express delivery companies can reduce the frequency of use of taxis and private cars. While bringing convenience to residents' lives, the express delivery industry also helps reduce carbon emissions from the transportation sector. Correspondingly, with the support of a series of government policies, the express delivery industry has shown an explosive development trend in China, and the massive energy consumption and carbon emissions caused by express transportation are becoming increasingly serious. In addition, due to the inefficient allocation of express resources, and the lack of advanced low-carbon technologies and effective emission control measures, energy 
waste in express transportation is common. This will also lead to more unnecessary carbon emissions. From a technical perspective, this paper obtains ECDI through a normative calculation, namely the entropy method, and the weight of the per capita express delivery amount exceeds half of the three indicators. This means that the express delivery amount plays the largest role in ECDI. Meanwhile, Hypotheses $\mathrm{H} 1-\mathrm{H} 3$ predict that the relationships between the three indicators and the transportation sector's carbon emissions are quadratic, positive linear, and negative linear, respectively. Therefore, we guess that the impact of ECDI on the transportation sector's carbon emissions may be quadratic and has an inflection point. Taken together, this study predicts that ECDI has a U-shaped effect on transportation sector's $\mathrm{CO}_{2}$ emissions. The fourth hypothesis $(\mathrm{H} 4)$ is as follows.

Hypothesis 4 (H4). There is a U-shaped relationship between ECDI and the transportation sector's $\mathrm{CO}_{2}$ emissions.

\subsubsection{Control Variables}

According to existing research, five indicators (economic development level, residential income level, educational level, transportation convenience level, and urban population density) that may affect the transportation sector's carbon emissions are included in the regression models as control variables.

This study uses the total GDP of a certain region in that year to represent the overall level of regional economic development and uses the per capita disposable income of urban households to represent the income level of residents. Studies have shown that the growth of economy and income are the main factors leading to the increase in the transportation sector's $\mathrm{CO}_{2}$ emissions [52-55]. Meanwhile, in order to eliminate the impact of inflation, this paper uses the Consumer Price Index (CPI) to convert the regional GDP and per capita disposable income of urban households into constant price values based on 2008 .

Educational level is measured by the average number of students in colleges and universities per 100,000 people. On the one hand, well-educated people are more likely to use low-carbon transportation and are more willing to pay higher prices for environmentally friendly products and clean energy, which helps to change energy consumption structure and reduce carbon emissions [56]. On the other hand, improving educational level can stimulate consumption (e.g., buying private cars, online shopping, and ordering take-out) by increasing personal income $[57,58]$. These behaviors will increase energy consumption and carbon emissions. Under the influence of these two factors, the impact of educational level on the transportation sector's carbon emissions is uncertain and may vary regionally.

This study uses per capita urban road area to measure the level of transportation convenience. Improving transportation convenience level and road capacity will encourage driving, thus increasing fuel consumption and $\mathrm{CO}_{2}$ emissions from the transportation sector [59]. In addition, urban population density is also an important control variable. With the concentration of urban population, the same express distribution range and routes can cover more customers. At the same time, in a compact and high-density urban form, the government is more likely to take advantage of an agglomeration effect to provide a relatively well-developed public transportation service system [60-63]. Therefore, this paper predicts that urban population density has a negative correlation with the transportation sector's $\mathrm{CO}_{2}$ emissions [64].

\subsection{Data Sources}

China is a vast territory country, with numerous cities and a large population base. In view of the availability of data, this study selects the relevant data of 30 provincial administrative units (except Tibet) in mainland China from 2008 to 2017 for quantitative regression analysis. Taking into account the regional heterogeneity, we need to conduct sub-regional research. According to official documents [65-67], this paper divides 30 provinces into three different regions, namely, the Western, Central and Eastern regions (see Figure 5 and Table 2). There are certain similarities in the natural environment, socio-economic 
conditions, residents' living habits, and cultural traditions within each region. The Western region is geographically remote, sparsely populated, and has inconvenient transportation. Most provinces within the region are rich in natural resources, but economically backward. The provinces in the Central region are mainly located in Central and Northeastern China, with sub-developed economies, large populations, and sufficient labor. Most provinces in the Eastern region are coastal and strategically located, with high levels of economy, technology, and education. Due to the differences in spatial location, economic foundation, industrial structure, and resource endowment, the development level of the express delivery industry and the emission reduction capabilities of the transportation sector in each region are different [68]. Tables 3 and 4 provide variable descriptions, data sources, and descriptive statistics, respectively. In addition, considering that the high correlation between the independent variables will affect the accuracy of the model estimation, we further use the Variance Inflation Factor (VIF) to test the multicollinearity of the variables $[69,70]$. The results show that there is no multicollinearity among the variables in this study, which reveals the reliability of the regression results to a certain extent (see Table 5).

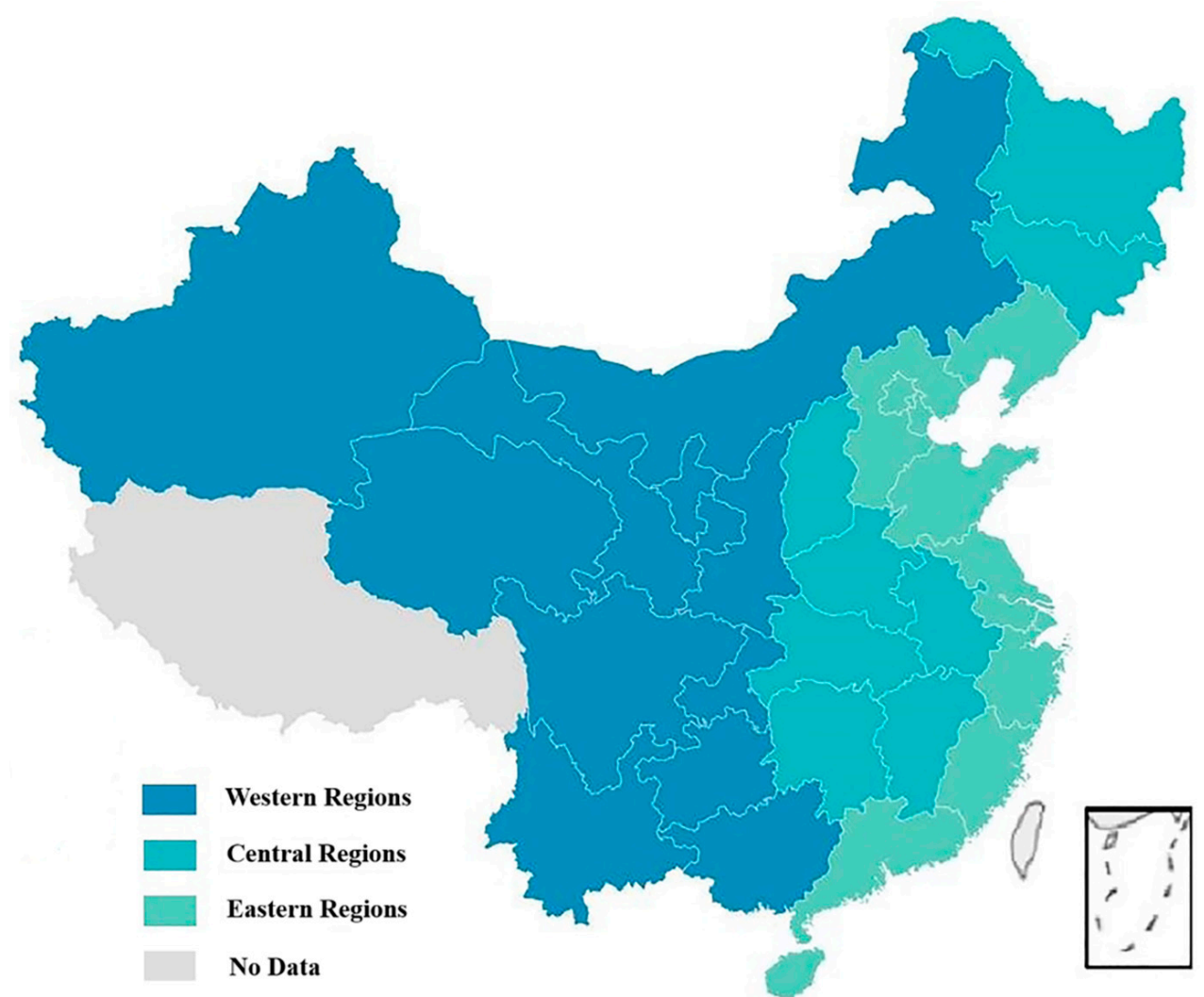

Figure 5. Spatial distribution map of the three regions in mainland China. Note: The map of China comes from public sources.

Table 2. The specific division of the three regions in mainland China.

\begin{tabular}{cc}
\hline Regions & Province \\
\hline The Western Region & $\begin{array}{r}\text { Inner Mongolia, Guangxi, Chongqing, Sichuan, Guizhou, Yunnan, } \\
\text { Shaanxi, Gansu, Qinghai, Ningxia, Xinjiang }\end{array}$ \\
\hline The Central Region & Shanxi, Jilin, Heilongjiang, Anhui, Jiangxi, Henan, Hubei, Hunan \\
\hline The Eastern Region & $\begin{array}{c}\text { Beijing, Tianjin, Hebei, Liaoning, Shanghai, Jiangsu, Zhejiang, } \\
\text { Fujian, Shandong, Guangdong, Hainan }\end{array}$ \\
\hline
\end{tabular}


Table 3. Variables, measurement, and data sources.

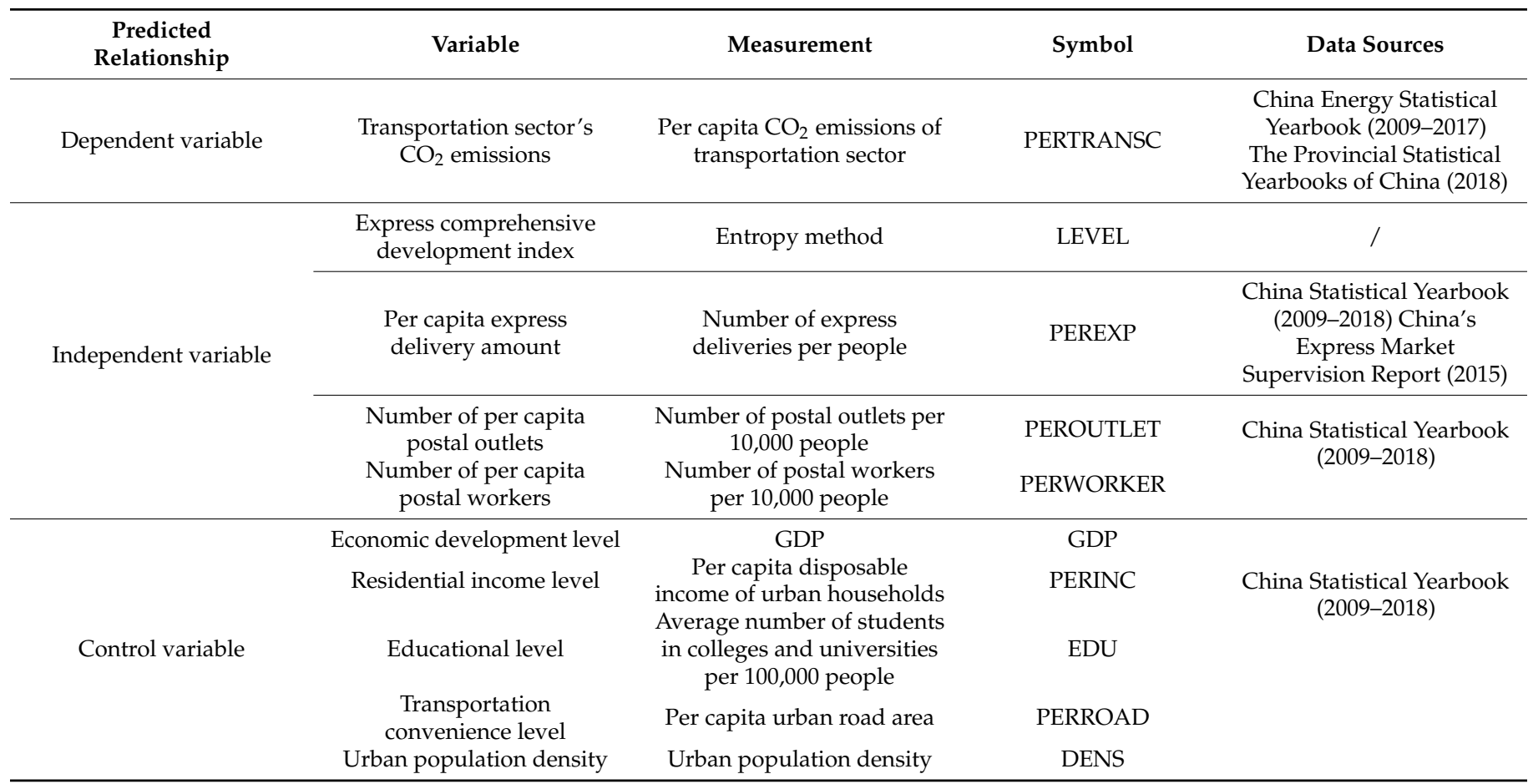

Table 4. Descriptive statistics.

\begin{tabular}{cccccc}
\hline Variable & Observations & Mean & Std.Dev. & Min & Max \\
\hline PERTRANSC & 300 & 0.677 & 0.433 & 0.183 & 3.040 \\
PEREXP & 300 & 9.383 & 14.063 & 0.453 & 100.646 \\
PEROUTLET & 300 & 1.035 & 0.701 & 0.279 & 6.772 \\
PERWORKER & 300 & 6.290 & 4.946 & 1.666 & 38.868 \\
GDP & 300 & 1.742 & 1.398 & 0.102 & 7.444 \\
PERINC & 300 & 2.163 & 0.719 & 1.097 & 5.137 \\
EDU & 300 & 0.246 & 0.091 & 0.097 & 0.675 \\
PERROAD & 300 & 14.275 & 4.461 & 4.040 & 25.820 \\
DENS & 300 & 0.280 & 0.120 & 0.065 & 0.597 \\
\hline
\end{tabular}

Table 5. VIF value of each variable.

\begin{tabular}{ccc}
\hline Variable & VIF & $\mathbf{1 / V I F}$ \\
\hline PERINC & 7.19 & 0.138993 \\
PEREXP & 6.03 & 0.165840 \\
PEROUTLET & 4.39 & 0.227994 \\
PERWORKER & 2.61 & 0.383323 \\
EDU & 2.16 & 0.463452 \\
GDP & 1.92 & 0.521091 \\
PERROAD & 1.55 & 0.644326 \\
DENS & 1.23 & 0.814237 \\
Mean VIF & 3.38 & \\
\hline
\end{tabular}

\subsection{Model Construction}

There are three main methods to deal with panel data, namely, the mixed OLS model, fixed effects model, and random effects model. Firstly, this paper conducted the Hausman test, judging the random effects model and the fixed effects model. The test results rejected the null hypothesis (i.e., random effects model), indicating that the fixed effects model should be selected. Then it used the F-test to judge the mixed OLS model and fixed effects 
model. The test results rejected the null hypothesis (i.e., mixed OLS model), indicating that the panel data in this paper still support the fixed effects model. In addition, some scholars pointed out that the fixed effects model is more appropriate when studying the entire population [71]. Therefore, this study finally selected the individual fixed effects model for regression analysis.

According to Hypotheses H1-H3, this study uses three major indicators as independent variables to establish the regression equation that includes the quadratic term of per capita express delivery amount (see Equation (2)). Next, we establish a second regression equation with the linear and quadratic terms of ECDI as independent variables (see Equation (3)).

$$
\begin{gathered}
Y_{i t}=\alpha_{0}+\alpha_{1} \text { PEREXP }_{i t}+\alpha_{2} \text { PEREXP }_{i t}^{2}+\alpha_{3} \text { PEROUTLET }_{i t}+\alpha_{4} \text { PERWORKER }_{i t} \\
+\alpha_{5} \text { GDP }_{i t}+\alpha_{6} \text { PERINC }_{i t}+\alpha_{7} \text { EDU }_{i t}+\alpha_{8} \text { PERROAD }_{i t} \\
+\alpha_{9} D E N S_{i t}+\delta_{i}+\varepsilon
\end{gathered}
$$

where $i$ denotes the 30 provincial administrative units in mainland China involved in this paper, $t$ denotes the time phase (2008-2017), $Y_{i t}$ denotes transportation sector's $\mathrm{CO}_{2}$ emissions in province $i$ in year $t, P E R E X P_{i t}$ denotes per capita express delivery amount, PEROUTLET $T_{i t}$ denotes number of per capita postal outlets, PERWORKER $i t$ denotes number of per capita postal workers, and $L E V E L_{i t}$ denotes ECDI. GDP $P_{i t}$ denotes economic development level, $P E R I N C_{i t}$ denotes residential income level, $E D U_{i t}$ denotes educational level, $P E R R O A D_{i t}$ denotes transportation convenience level, and $D E N S_{i t}$ denotes urban population density. In addition, $\alpha_{0}$ and $\beta_{0}$ denote the constant term, $\alpha_{i}$ and $\beta_{i}$ denote the corresponding correlation coefficients, $\delta_{i}$ denotes the individual fixed effects, and $\varepsilon$ is the error item.

\section{Empirical Analysis Results and Discussion}

4.1. Three Major Indicators and Transportation Sector's $\mathrm{CO}_{2}$ Emissions

4.1.1. Nationwide Regression Results

Firstly, this paper obtained the nationwide regression results with the three indicators (per capita express delivery amount, number of per capita postal outlets, and number of per capita postal workers) of the express delivery industry's development as independent variables (see Table 6). Among them, the second to fourth columns show the impact of a single indicator on the transportation sector's $\mathrm{CO}_{2}$ emissions, respectively. The fifth column describes the regression results of incorporating three indicators into the model simultaneously. In addition, the R-squared of the four models are all greater than 0.5, indicating that all models fit well.

Table 6. Nationwide regression results (three major indicators).

\begin{tabular}{ccccc}
\hline PERTRANSC & Model 1 & Model 2 & Model 3 & Model 4 \\
\hline PEREXP & $-0.004015^{*}$ & & & $-0.004851^{* *}$ \\
& $(0.001572)$ & & & $(0.001665)$ \\
PEREXP2 & $0.000068^{* * *}$ & & & $0.000063^{* * *}$ \\
& $(0.000014)$ & & & $(0.000015)$ \\
PEROUTLET & & $0.045133^{* *}$ & & $0.030717^{*}$ \\
PERWORKER & & $(0.013905)$ & & $(0.016833)$ \\
GDP & & & $-0.006587^{*}$ & -0.002469 \\
& & & $(0.002550)$ & $(0.002628)$ \\
PERINC & $(0.016414)$ & $(0.016104)$ & $-0.034665^{*}$ & -0.019265 \\
& $0.145445^{* * *}$ & $0.111292^{* * *}$ & $0.180508^{* * *}$ & $(0.017162)$ \\
& $(0.029711)$ & $(0.027699)$ & $(0.021077)$ & $0.138671^{* * *}$ \\
\hline
\end{tabular}


Table 6. Cont.

\begin{tabular}{ccccc}
\hline PERTRANSC & Model 1 & Model 2 & Model 3 & Model 4 \\
\hline \multirow{2}{*}{ EDU } & $1.113227^{* * *}$ & $0.729109 * *$ & $0.773565^{* *}$ & $0.907678^{* *}$ \\
& $(0.246471)$ & $(0.248665)$ & $(0.249399)$ & $(0.267241)$ \\
PERROAD & 0.006998 & 0.003500 & 0.001574 & 0.006143 \\
& $(0.004545)$ & $(0.004382)$ & $(0.004342)$ & $(0.004550)$ \\
DENS & -0.138316 & -0.193122 & -0.136317 & -0.128855 \\
& $(0.118442)$ & $(0.122563)$ & $(0.124936)$ & $(0.119241)$ \\
_cons & 0.096683 & $0.278338^{* * *}$ & $0.213822^{* * *}$ & $0.146975^{*}$ \\
N & $(0.064402)$ & $(0.064655)$ & $(0.062206)$ & $(0.069206)$ \\
R2 & 300 & 300 & 300 & 300 \\
*,**, and *** indicate significance levels of $10 \%, 5 \%$, and 1\%, respectively. & 0.5049 & 0.5552 \\
\hline
\end{tabular}

In the fifth column, the linear coefficient of per capita express delivery amount is significantly negative at the $5 \%$ level, while the one for quadratic term is significantly positive at the $1 \%$ level, which is quite different from previous research conclusions. Most of the existing studies argue that the growth of express delivery amount will greatly increase carbon emissions, ignoring that the scale effect of express transportation may bring about emission reduction effects. This paper incorporated the quadratic term of the express delivery amount into the model and found that there is a significant U-shaped relationship between express delivery amount and carbon emissions, which verifies hypothesis H1. Based on this, we drew the scatter plot of per capita express delivery amount and the transportation sector's $\mathrm{CO}_{2}$ emissions, along with a fitted curve (i.e., blue solid line) and 95\% confidence interval (see Figure 6). This roughly shows the U-shaped relationship between the two variables, and the per capita express delivery amount at the inflection point of the $\mathrm{U}$-shaped curve is about 38 pieces. That is, from a nationwide perspective, when the per capita express delivery amount is less than 38 , the transportation sector's $\mathrm{CO}_{2}$ emissions show a downward trend. Once the per capita express delivery amount exceeds 38 pieces, $\mathrm{CO}_{2}$ emissions will increase accordingly. However, it has to be mentioned that the U-shaped trend of the fitted curve is not significant. There are two main reasons. Firstly, due to the limitations of data acquisition, this paper only uses the data from 2008 to 2017 for the related research. The lack of data in 2018, 2019, and 2020 may weaken the U-shaped trend of the fitted curve. Secondly, during the study period (2008-2017), the per capita express delivery amount in most provinces of China is lower. As shown in Figure 6, most of the scattered points are concentrated on the left side of the inflection point, while only a few points are located on the right side of the inflection point or near the inflection point. Therefore, in data visualization analysis, the fitting effect of the U-shaped curve will inevitably be weakened to some extent. In view of the above two reasons, although the regression results of Model 4 show that the per capita express delivery amount has a significant U-shaped effect on the transportation sector's carbon emissions, the U-shaped trend of the fitting curve still has a lot of room for improvement. In addition, in the fifth column, the coefficient of postal outlets' number is significantly positive, thus verifying hypothesis H2. However, the emission reduction effect of postal workers' number does not appear, which may be related to regional heterogeneity.

For Model 4 in Table 6, the regression results of control variables are worth noting. The regression coefficients of residents' income and educational level are significantly positive. That is, the increase of residents' income and educational level can promote carbon emissions from transportation sector. However, the regression coefficients of economic development level, transportation convenience level, and urban population density are not statistically significant, which may be related to regional heterogeneity. Therefore, this paper will continue to conduct sub-regional analysis to explore regional heterogeneity. 


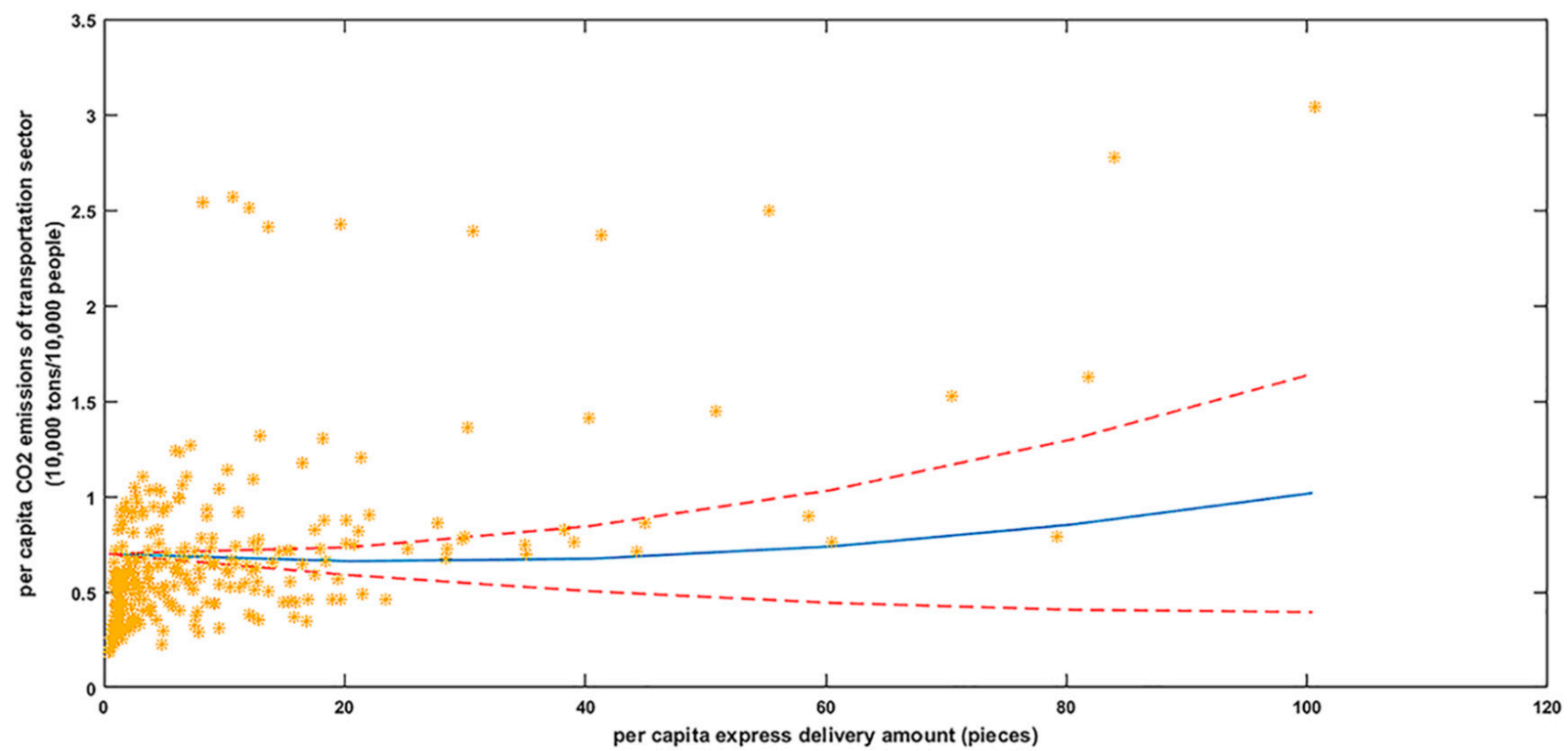

Figure 6. Scatter plot of the per capita express delivery amount and the transportation sector's $\mathrm{CO}_{2}$ emissions. Note: The blue solid line represents the fitted curve, and the part between the two red dashed lines represents the $95 \%$ confidence interval.

\subsubsection{Sub-Regional Regression Results}

Table 7 presents the regression results of the Western, Central, and Eastern regions that incorporate the three independent variables simultaneously, respectively.

Table 7. Sub-regional regression results (three major indicators).

\begin{tabular}{cccc}
\hline PERTRANSC & Western & Central & Eastern \\
\hline PEREXP & -0.010477 & $-0.014347^{*}$ & -0.002435 \\
& $(0.009115)$ & $(0.005922)$ & $(0.002373)$ \\
PEREXP2 & 0.000378 & $0.000589^{* *}$ & $0.000066^{* *}$ \\
& $(0.000334)$ & $(0.000188)$ & $(0.000022)$ \\
PEROUTLET & -0.051005 & -0.026558 & 0.011096 \\
PERWORKER & $(0.041871)$ & $(0.039930)$ & $(0.026262)$ \\
GDP & $-0.017188^{* *}$ & $0.012043^{*}$ & 0.002163 \\
& $(0.005400)$ & $(0.005345)$ & $(0.003987)$ \\
PERINC & $-0.162355^{* *}$ & 0.047753 & 0.004277 \\
& $(0.060689)$ & $(0.042837)$ & $(0.026462)$ \\
EDU & $0.404660^{* * *}$ & $0.188431 * *$ & 0.037854 \\
& $(0.073318)$ & $(0.067868)$ & $(0.052499)$ \\
PERROAD & $1.531499^{*}$ & -0.990104 & 0.665881 \\
& $(0.637143)$ & $(0.638357)$ & $(0.493087)$ \\
DENS & -0.004191 & $0.012429 *$ & 0.004626 \\
& $(0.005828)$ & $(0.007228)$ & $(0.010422)$ \\
_COns & 0.021847 & -0.179013 & -0.563212 \\
N & $(0.138652)$ & $(0.169463)$ & $(0.487232)$ \\
R2 & -0.091699 & 0.142309 & $0.658457 * *$ \\
& $(0.107081)$ & $(0.112305)$ & $(0.230239)$ \\
\hline
\end{tabular}

${ }^{* * *}$, and ${ }^{* * *}$ indicate significance levels of $10 \%, 5 \%$, and $1 \%$, respectively.

The Western region: In the regression results, the coefficient of per capita postal workers' number is negative, which verifies hypothesis $\mathrm{H} 3$. The Western region is vast and sparsely populated, which makes the local express delivery service mainly rely on postal workers and electric vehicles. Therefore, increasing the number of postal workers can help reduce carbon emissions from transportation sector. However, the coefficients of per 
capita express delivery amount and per capita postal outlets' number are not significant. In fact, in view of the high logistics costs and weak infrastructure, the development of the express delivery industry in the Western region has been greatly restricted, and the express delivery amount and postal outlets' number remains small. Therefore, even if the express delivery amount or postal outlets' number increases, their impact on the carbon emissions of the transportation sector is still weak. Furthermore, due to the low level of economic development in the Western region, with GDP growth, local governments will have additional funds to invest in the transportation sector (e.g., technology, equipment, personnel), which will help to improve the efficiency of transportation management, strengthen operational levels, and reduce carbon emissions. Therefore, the coefficient of GDP is significantly negative. Currently, private car ownership in the Western region is low but growing rapidly [72]. Both the direct increase in residents' income and the indirect increase due to education will further promote car consumption and increase the transportation sector's carbon emissions, which is consistent with the significant positive coefficients of residential income level and educational level.

The Central region: The significant U-shaped relationship between per capita express delivery amount and the transportation sector's $\mathrm{CO}_{2}$ emissions has verified hypothesis H1. However, the coefficient of the number of per capita postal workers is significantly positive, which is inconsistent with hypothesis H3. Regarding this interesting result, we will analyze it from two perspectives based on the actual situation in the Central region. Firstly, although the large rural population in the Central region can provide sufficient labor for the development of the local express delivery industry, their generally weak low-carbon awareness will inevitably lead to lower resource utilization efficiency and serious energy waste. Secondly, due to the lack of senior express management talents, the management level of the express delivery industry is lower, and the express service scope and resource allocation are unreasonable, which also lead to unnecessary energy consumption and carbon emissions. Therefore, the postal workers' number in the Central region will increase the carbon emissions of local transportation sector. In addition, similar to the Western region, the increase in residents' income can promote the transportation sector's carbon emissions by stimulating consumption. Meanwhile, local governments strongly support the construction of transportation infrastructure to give full play to the role of transportation hubs in the Central region, which will improve transportation convenience level, promote driving, and significantly increase carbon emission.

The Eastern region: Although the coefficient of the per capita express delivery amount has verified hypothesis H1, compared with the Central and Western regions, most of the parameters in the Eastern region model are not statistically significant, which requires in-depth analysis based on local conditions. In recent years, the express delivery amount in Eastern China has accounted for more than $75 \%$ of the total express delivery amount in the country. After long-term development, the express delivery service network in most cities of the Eastern region has been relatively complete, and the layout and structure of postal outlets and postal workers are relatively stable, gradually forming four regional express delivery circles centered on large coastal cities. Based on the above analysis, the impact of the number of postal outlets and postal workers on carbon emissions will be minimal. Furthermore, due to the relatively developed public transportation service network in the Eastern region, local residents have developed a fixed riding habit, and will remain stable in a short period of time, thus indicating that the influences of control variables on the transportation sector's carbon emissions can be ignored. In summary, the regression results of variables in the Eastern region model are reasonable and acceptable.

Interestingly, the regression results of urban population density in Tables 6 and 7 are inconsistent with our expectations. In the Central and Eastern regions, the urban population density has reached saturation, and the pressure on the service network of express delivery companies has always been high. Therefore, there is little room to reduce carbon emissions from local transportation sectors by increasing population density, which is consistent with the fact that the coefficients of urban population density are negative 
but insignificant. On the contrary, the urban population density in the Western region is lower. As more and more people flow into cities, residents' demand for express delivery services will continue to increase, thus leading to more energy consumption and carbon emissions [73]. All in all, compared with previous qualitative analysis, the above analysis can provide data support and empirical evidence for local governments to formulate emission reduction policies and measures according to local conditions.

\subsection{ECDI and Transportation Sector's $\mathrm{CO}_{2}$ Emissions}

In order to further explore the relationship between the express delivery industry's development and the transportation sector's carbon emissions, we use ECDI as an independent variable to perform nationwide and sub-regional regressions. The results are shown in Table 8. In nationwide regression results (i.e., the second column), the coefficient of linear ECDI term is significantly negative at the $5 \%$ level, while the one for the quadratic term is significantly positive at the $1 \%$ level, thus verifying hypothesis $\mathrm{H} 4$. Next, we drew the scatter plot, along with a fitted curve (i.e., blue solid line) and $95 \%$ confidence interval (see Figure 7). Among them, the ECDI value at the inflection point of the fitted curve is 0.26. Similar to the analysis in Section 4.1.1, the generally lower ECDI value means that most provinces are located on the left side of the inflection point or near the inflection point, which partly explains why the U-shaped trend of the fitted curve is slightly flat. Fortunately, compared with Figure 6, Figure 7 shows more clearly the U-shaped relationship between ECDI and the transportation sector's carbon emissions. In addition, for the provinces located in the upper right corner of Figure 7, the rapid development of local express delivery industries is accompanied by excessive resource input and serious energy waste, such as blindly increasingly postal outlets and diesel vehicles. The extensive expansion mode of the express delivery industry will lead to excessive carbon emissions, which is not conducive to the sustainable development of the region. Therefore, local governments and express delivery companies should actively innovate management methods to promote low-carbon intensive development of the express delivery industry, especially for the provinces located on the right side of the inflection point and those near the point. Meanwhile, observing the third to fifth columns of Table 8, there is also a significant U-shaped relationship between ECDI and carbon emissions in the Eastern, Central, and Western regions, which has verified the robustness of the model. Due to space limitations, this paper will not make a detailed analysis. Interestingly, unlike previous studies that only focused on linear relationships, the nationwide and sub-regional results in Table 8 once again verified that the express delivery industry has a U-shaped effect on the carbon emissions of the transportation industry.

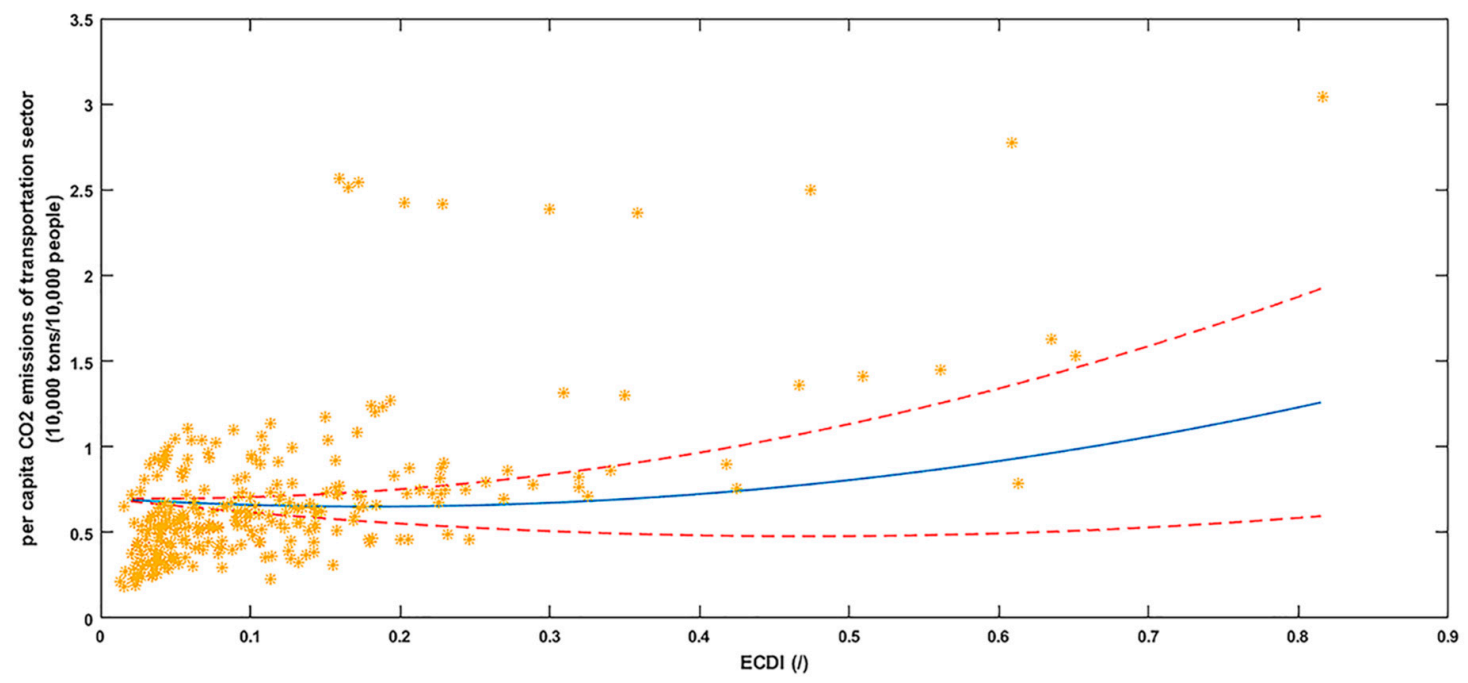

Figure 7. Scatter plot of ECDI and the transportation sector's $\mathrm{CO}_{2}$ emissions. Note: The blue solid line represents the fitted curve, and the part between the two red dashed lines represents the $95 \%$ confidence interval. 
Table 8. Regression results (ECDI).

\begin{tabular}{ccccc}
\hline PERTRANSC & Nationwide & Western & Central & Eastern \\
\hline \multirow{2}{*}{ LEVEL } & $-0.682560^{* *}$ & $-3.915887^{* * *}$ & -1.102910 & -0.534226 \\
& $(0.214564)$ & $(0.856920)$ & $(0.709720)$ & $(0.329974)$ \\
LEVEL2 & $1.297868^{* * *}$ & $10.329440^{* * *}$ & $4.216907^{*}$ & $1.377253^{* * *}$ \\
& $(0.227408)$ & $(2.820370)$ & $(2.336949)$ & $(0.322233)$ \\
GDP & -0.024993 & $-0.227138^{* * *}$ & $0.117520^{* * *}$ & 0.011217 \\
& $(0.016096)$ & $(0.053946)$ & $(0.035542)$ & $(0.024962)$ \\
PERINC & $0.140728^{* * *}$ & $0.457119^{* * *}$ & 0.088054 & 0.050063 \\
EDU & $(0.030568)$ & $(0.061834)$ & $(0.062217)$ & $(0.048996)$ \\
& $1.396862^{* * *}$ & $2.323015^{* * *}$ & $-1.221812 *$ & $1.062186^{*}$ \\
PERROAD & $(0.251482)$ & $(0.639382)$ & $(0.677057)$ & $(0.433681)$ \\
& $0.007323^{*}$ & -0.006486 & $0.016458^{*}$ & 0.003764 \\
DENS & $(0.004416)$ & $(0.005600)$ & $(0.007564)$ & $(0.009540)$ \\
& -0.108547 & -0.009297 & -0.031702 & -0.411667 \\
_cons & $(0.118107)$ & $(0.129779)$ & $(0.164797)$ & $(0.473889)$ \\
$\mathrm{N}$ & 0.041924 & $-0.194287^{*}$ & $0.211694 *$ & $0.518389^{*}$ \\
R2 & $(0.068532)$ & $(0.092833)$ & $(0.121521)$ & $(0.220171)$ \\
& 300 & 110 & 80 & 110 \\
$* * * *$, and & $* * *$ indicate significance levels of $10 \%, 5 \%$, and $1 \%$, respectively. & 0.5206 \\
\hline
\end{tabular}

Furthermore, it is necessary to elaborate on the reliability of empirical results, which mainly includes four aspects. First of all, compared with the time series data and crosssectional data in previous studies, the ten-year balanced panel data used in this study can comprehensively reflect the dynamic behavior information of the samples, reduce the collinearity among variables, and improve the reliability and effectiveness of parameter estimation [74]. Secondly, taking into account the differences in the provinces, this study applies the individual fixed-effect model for regression analysis, which helps to alleviate the problem of missing variables that are time-invariant but individually varying. Thirdly, we incorporate multiple control variables that may affect the transportation industry's carbon emissions into the models, which also weakens the estimation bias caused by missing variables. Finally, on the basis of nationwide and sub-regional regressions using the three indicators as independent variables (see Tables 6 and 7), we also conduct a corresponding regression analysis using ECDI as the independent variable (see Table 8). Fortunately, the regression results basically confirmed the U-shaped effect of the express delivery industry on carbon emissions; that is, the regression results are robust. On the whole, the above analysis shows that the models and regression results of this study are reliable.

\section{Conclusions and Policy Recommendations}

As an important part of the service industry, the explosive growth of the express delivery industry has promoted the national economy and facilitated residents' lives, but it has also led to a series of environmental problems. This paper focuses on the carbon emission problems caused by the express delivery industry. Firstly, we introduce the important role of the express industry in the national economy and people's livelihood and the current status of carbon emissions, and we review the relevant literature. Then, we introduce the core independent variables, namely the three indicators of the express delivery industry's development (per capita express delivery amount, number of per capita postal outlets, and number of per capita postal workers) and ECDI (obtained by entropy method), put forward the main research hypotheses, and construct the econometric models containing quadratic terms. Once more, we separately examine and discuss the actual impact of the three indicators and ECDI on the transportation sector's carbon emissions, respectively. Finally, we summarize and discuss the research conclusions and provide policy recommendations.

The main findings of this paper are as follows: (1) Express delivery amount has a significant U-shaped effect on the transportation sector's carbon emissions. In other 
words, given the scale effect of large-scale transportation, within a certain limit (i.e., the 38 pieces discussed above), the increase in express delivery amount will help to reduce carbon emissions. However, when the express delivery amount exceeds 38 pieces, the emission reduction effect produced by the scale effect will be greatly weakened, which will significantly increase the transportation sector's carbon emissions. (2) Postal workers are important participants and promoters of the low-carbon development of the express delivery industry. The reasonable allocation of postal outlets and postal workers has a certain potential for emission reduction. (3) There is a significant U-shaped relationship between ECDI and the transportation sector's carbon emissions, whether it is nationwide or sub-regional. The above research results indicate that taking measures to postpone the emergence of the inflection point of the U-shaped curve is essential for promoting the low-carbon transformation of the express delivery industry, as well as for balancing economic and environmental benefits. All in all, the main hypothesis of this paper has been verified.

Although this paper has achieved some valuable findings, there are still some limitations. In view of the availability of data, this paper only discusses the carbon emissions during express transportation, while it does not consider the carbon emissions from express package storage and express package waste landfills (e.g., woven bag, plastic bag, carton, and bubble film). In future research, we may consider including the entire process of express transportation, warehousing, distribution, and landfilling into the system dynamics model, including the express delivery industry's development subsystem, transportation sector subsystem, and ecological environment subsystem. By exploring the causal relationships and influence mechanisms among various subsystems, we may more comprehensively and accurately predict the actual impact of the express delivery industry on the ecological environment under different situations, thus seeking appropriate solutions to alleviate environmental pressure.

Based on the findings of this study, we propose the following policy recommendations.

(1) Express delivery companies should evaluate the operational capabilities of each outlet based on actual local conditions (e.g., express delivery amount, traffic conditions, consumption level, and customer concentration situations), and then decide whether to expand, split, or close that postal outlet. At the same time, express delivery companies should gradually incorporate the purchase of new energy vehicles and electric heavyduty trucks, as well as the establishment of smart express boxes and express delivery cooperation points in densely populated areas (e.g., CBD, residential areas, schools) into their corporate development plans. In addition, in the long run, it is necessary to strengthen school-enterprise cooperation, train express management talents, and establish talent echelons, while at the same time regulating the low-carbon behavior of postal workers through training and incentive mechanisms.

(2) Government action is helpful to alleviate or even explicitly solve the problems studied in this paper. For the Central and Western regions, local governments should seize the opportunity of rapid development, incorporate the low-carbon transformation of the express delivery industry into the overall planning of the logistics industry, and give full play to the effect of industrial agglomeration. For the Eastern region, local governments should integrate postal outlets as public service facilities into urban planning and strictly control the use of high-pollution diesel vehicles through intervention. In fact, some governments have formulated action plans related to emissions reduction. For example, the U.K. will ban the sale of new petrol and diesel cars and vans as of 2030, which is 10 years earlier than the original plan. British Prime Minister Boris Johnson also said that 250,000 high skill green jobs will be created and supported by 2030. Ireland, Denmark, Norway, the Netherlands, Scotland, and France have also formulated exit timetables for fuel vehicles. In addition, the German government has agreed to provide $€ 5$ billion of aid to the country's auto industry to support the transition to electric cars and encourage the replacement of old trucks. It is worth noting that in order to achieve emission reduction 
targets, the governments need to continuously strengthen and improve their emission reduction measures and develop more detailed action plans.

Author Contributions: Conceptualization, C.Z. and B.Z.; methodology, C.Z. and B.Z.; software, C.Z. and B.Z.; validation, C.Z.; formal analysis, C.Z. and B.Z.; writing - original draft preparation, C.Z.; writing-review and editing, C.Z. and B.Z.; visualization, C.Z. and B.Z.; supervision, C.Z. and B.Z.; project administration, B.Z.; funding acquisition, B.Z. All authors have read and agreed to the published version of the manuscript.

Funding: This research was funded by the National Social Science Fund of China (Youth Project No. 19CGL051), the Fundamental Research Funds for the Central Universities, ZUEL (Project No. 2722020JCG058), the Research Initiation Grant Program for the Introduction of Talent, ZUEL, and the Fundamental Research Funds for the Central Universities, HUST (Project No. 2018JYCXJJ050).

Institutional Review Board Statement: Not applicable.

Informed Consent Statement: Not applicable.

Data Availability Statement: In this study, the data were mainly obtained from State Post Bureau of the People's Republic of China, China Statistical Yearbook, China Energy Statistical Yearbook, China Express Development Index Report, China's Express Market Supervision Report.

Acknowledgments: The authors would like to acknowledge Yiming Xiao and Hong Mei for their support and help for the paper.

Conflicts of Interest: The authors declare no conflict of interest.

\section{Appendix A}

The specific calculation steps of the entropy method to calculate ECDI are as follows.

(1) To process the original data with a nonzero standardization,

$$
y_{k i j}=\frac{\left\{x_{k i j}-\min \left(x_{k i j}\right)\right\}}{\left\{\max \left(x_{k i j}\right)-\min \left(x_{k i j}\right)\right\}} \times 0.99+0.01
$$

where $x_{k i j}$ represents the original data of the $j t h$ major indicator of the express delivery industry's development of the $k t h$ province in the ith year, $k=1,2, \ldots, 30 ; j=1,2,3$; ;

(2) To calculate the proportion of the $j$ th major indicator of the express delivery industry's development of the kth province in the ith year;

$$
\mu_{k i j}=\frac{y_{k i j}}{\sum_{k} \sum_{i} y_{k i j}}
$$

(3) To calculate the entropy and coefficient of variation of the $j$ th major indicator of express delivery industry development, where the number of provincial administrative units is $30(r=30)$, and the number of years is $10(m=10)$;

$$
\begin{gathered}
e_{j}=-\frac{1}{\ln (r \times m)} \times \sum_{k} \sum_{i}\left(\mu_{k i j} \times \ln \mu_{k i j}\right) \\
d_{j}=1-e_{j}
\end{gathered}
$$

(4) To calculate the weight of the $j$ th major indicator of express delivery industry development in the comprehensive evaluation;

$$
\omega_{j}=\frac{d_{j}}{\sum_{j} d_{j}}
$$


(5) To calculate ECDI of various provincial administrative units in the ith year, where when $s_{k i}$ is higher, the development level of the express delivery industry is higher.

$$
s_{k i}=\sum_{j} \omega_{j} \times y_{k i j}
$$

\section{References}

1. Fan, W.G.; Xu, M.; Dong, X.B.; Wei, H.J. Considerable Environmental Impact of the Rapid Development of China's Express Delivery Industry. Resour. Conserv. Recycl. 2017, 126, 174-176. [CrossRef]

2. Chen, H.; Long, R.Y.; Niu, W.J.; Feng, Q.; Yang, R.R. How Does Individual Low-Carbon Consumption Behavior Occur?-An Analysis Based on Attitude Process. Appl. Energy 2014, 116, 376-386. [CrossRef]

3. Visser, J.; Nemoto, T.; Browne, M. Home Delivery and the Impacts on Urban Freight Transport: A Review. Procedia Soc. Behav. Sci. 2014, 125, 15-27. [CrossRef]

4. State Post Bureau of the People's Republic of China. 2020 China Express Development Index Report (January to August). Available online: www.spb.gov.cn/sj/zgkdfzzs / (accessed on 28 March 2021).

5. Wang, J.X.; Lim, M.K.; Tseng, M.L.; Yang, Y. Promoting Low Carbon Agenda in the Urban Logistics Network Distribution System. J. Clean. Prod. 2019, 211, 146-160. [CrossRef]

6. Chen, T.; Lin, C.W. A Fuzzy Collaboration System for Ubiquitous Loading/Unloading Space Recommendation in the Logistics Industry. Robot. Comput. Integr. Manuf. 2017, 45, 86-98. [CrossRef]

7. Yang, B.; Guo, Y.Y.; Shi, X.; Lu, Y.Y. Research on the Energy Consumption Evaluation Model of Container Terminal Logistics System. Appl. Mech. Mater. 2012, 157, 1224-1229. [CrossRef]

8. Duan, H.B.; Song, G.H.; Qu, S.; Dong, X.B.; Xu, M. Post-Consumer Packaging Waste from Express Delivery in China. Resour. Conserv. Recycl. 2019, 144, 137-143. [CrossRef]

9. GF Securities. Quantitative Comparison of Tongda System Based on Dynamic Programming Modeling. Available online: www.doc88.com/p-5671609677886.html (accessed on 25 March 2021).

10. Kang, P.; Song, G.H.; Chen, D.J.; Duan, H.B.; Zhong, R.Y. Characterizing the Generation and Spatial Patterns of Carbon Emissions from Urban Express Delivery Service in China. Environ. Impact Assess. Rev. 2020, 80, 106336. [CrossRef]

11. Baral, N.R.; Asher, Z.D.; Trinko, D.; Sproul, E.; Quiroz-Arita, C.; Quinn, J.C.; Bradley, T.H. Biomass Feedstock Transport Using Fuel Cell and Battery Electric Trucks Improves Lifecycle Metrics of Biofuel Sustainability and Economy. J. Clean. Prod. 2021, 279, 123593. [CrossRef]

12. Harvey, L.D.D. Resource Implications of Alternative Strategies for Achieving Zero Greenhouse Gas Emissions from Light-Duty Vehicles By 2060. Appl. Energy 2018, 212, 663-679. [CrossRef]

13. Lee, D.Y.; Elgowainy, A.; Kotz, A.; Vijayagopal, R.; Marcinkoski, J. Life-Cycle Implications of Hydrogen Fuel Cell Electric Vehicle Technology for Medium-And Heavy-Duty Trucks. J. Power Sources 2018, 393, 217-229. [CrossRef]

14. Agence France-Presse. DHL Introduces ‘Green' Service in Asia Pacific. Available online: www.thedailystar.net/news-detail-26869 (accessed on 7 May 2021).

15. Rasool, Y.; Zaidi, S.A.H.; Zafar, M.W. Determinants of Carbon Emissions in Pakistan's Transport Sector. Environ. Sci. Pollut. Res. 2019, 26, 1-15. [CrossRef]

16. Trofimenko, Y.; Komkov, V.; Donchenko, V. Problems and Prospects of Sustainable Low Carbon Development of Transport in Russia. IOP Conf. Ser. Earth Environ. Sci. 2018, 177. [CrossRef]

17. Zhang, X.M.; Zhou, G.G.; Cao, J.; Wu, A.Q. Evolving Strategies of E-Commerce and Express Delivery Enterprises with Public Supervision. Res. Transp. Econ. 2020, 80. [CrossRef]

18. Shao, S.J.; Xu, G.Y.; Li, M.; Huang, G.Q. Synchronizing E-Commerce City Logistics with Sliding Time Windows. Transp. Res. Part E Logist. Transp. Rev. 2019, 123, 17-28. [CrossRef]

19. Pitney Bowes. Pitney Bowes Parcel Shipping Index. Available online: www.sohu.com/a/333085996_343156?scm=1002.46005d.16 b016f01a2.PC_ARTICLE_REC_OPT (accessed on 23 April 2021).

20. Liu, B.; Deng, C.Y.; Lin, J.L.; Huang, P. Discussion on Development Countermeasures of Railway Express Freight Transport Equipments. Railw. Freight Transp. 2014, 32, 9-14.

21. Barenji, A.V.; Wang, W.M.; Li, Z.; Guerra-Zubiaga, D.A. Intelligent E-Commerce Logistics Platform Using Hybrid Agent Based Approach. Transp. Res. Part E Logist. Transp. Rev. 2019, 126, 15-31. [CrossRef]

22. Anderhofstadt, B.; Spinler, S. Factors Affecting the Purchasing Decision and Operation of Alternative Fuel-Powered Heavy-Duty Trucks in Germany-A Delphi Study. Transp. Res. Part D Transp. Environ. 2019, 73, 87-107. [CrossRef]

23. Li, W.B.; Long, R.Y.; Chen, H.; Geng, J.C. A Review of Factors Influencing Consumer Intentions to Adopt Battery Electric Vehicles. Renew. Sustain. Energy Rev. 2017, 78, 318-328. [CrossRef]

24. Zhou, M.; Kong, N.; Zhao, L.D.; Huang, F.H.; Wang, S.; Campy, K.S. Understanding Urban Delivery Drivers' Intention to Adopt Electric Trucks in China. Transp. Res. Part D Transp. Environ. 2019, 74, 65-81. [CrossRef]

25. Weideli, D. Environmental Analysis of US Online Shopping. Available online: ctl.mit.edu/sites/default/files/library/public/ Dimitri-Weideli-Environmental-Analysis-of-US-Online-Shopping_0.pdf (accessed on 19 March 2021). 
26. Nguyen, N. The Hidden Environmental Cost of Amazon Prime's Free, Fast Shipping. Available online: depts.washington. edu/sctlctr/news-events/in-the-news/hidden-environmental-cost-amazon-prime $\% E 2 \% 80 \% 99$ s-free-fast-shipping (accessed on 21 April 2021).

27. Stolaroff, J.K.; Samaras, C.; O’Neill, E.R.; Lubers, A.; Mitchell, A.S.; Ceperley, D. Energy Use and Life Cycle Greenhouse Gas Emissions of Drones for Commercial Package Delivery. Nat. Commun. 2018, 9, 1-13. [CrossRef]

28. Steenhof, P.; Woudsma, C.; Sparling, E. Greenhouse Gas Emissions and the Surface Transport of Freight in Canada. Transp. Res. Part D Transp. Environ. 2006, 11, 369-376. [CrossRef]

29. Jin, M.Z.; Granda-Marulanda, N.A.; Down, I. The Impact of Carbon Policies on Supply Chain Design and Logistics of a Major Retailer. J. Clean. Prod. 2014, 85, 453-461. [CrossRef]

30. Behnke, M.; Kirschstein, T. The Impact of Path Selection on GHG Emissions in City Logistics. Transp. Res. Part E Logist. Transp. Rev. 2017, 106, 320-336. [CrossRef]

31. Velázquez-Martínez, J.C.; Fransoo, J.C.; Blanco, E.E.; Valenzuela-Ocaña, K.B. A New Statistical Method of Assigning Vehicles to Delivery Areas for $\mathrm{CO}_{2}$ Emissions Reduction. Transp. Res. Part D Transp. Environ. 2016, 43, 133-144. [CrossRef]

32. Bouchery, Y.; Fransoo, J. Cost, Carbon Emissions and Modal Shift in Intermodal Network Design Decisions. Int. J. Prod. Econ. 2015, 164, 388-399. [CrossRef]

33. Liu, F.; Klimont, Z.; Zhang, Q.; Cofala, J.; Zhao, L.J.; Huo, H.; Nguyen, B.; Schöpp, W.; Sander, R.; Zheng, B.; et al. Integrating Mitigation of Air Pollutants and Greenhouse Gases in Chinese Cities: Development of GAINS-City Model for Beijing. J. Clean. Prod. 2013, 58, 25-33. [CrossRef]

34. Wamsler, C.; Brink, E.; Rivera, C. Planning for Climate Change in Urban Areas: From Theory to Practice. J. Clean. Prod. 2013, 50, 68-81. [CrossRef]

35. Zhang, Y.; Chen, J.; Li, X.F.; Zhong, M.E. Exploring Logistics Dispatcher's Preference in Electric Tricycle Related Policies: The Case of China. J. Clean. Prod. 2019, 230, 835-843. [CrossRef]

36. IPCC. 2006 IPCC Guidelines for National Greenhouse Gas Inventories; IPCC: Geneva, Switzerland, 2006.

37. Chen, Y.L.; Zhao, J.C.; Lai, Z.Z.; Wang, Z.; Xia, H.B. Exploring the Effects of Economic Growth, and Renewable and NonRenewable Energy Consumption on China's $\mathrm{CO}_{2}$ Emissions: Evidence from a Regional Panel Analysis. Renew. Energy 2019, 140, 341-353. [CrossRef]

38. Du, H.B.; Chen, Z.N.; Peng, B.B.; Southworth, F.; Ma, S.; Wang, Y. What Drives $\mathrm{CO}_{2}$ Emissions from the Transport Sector? A Linkage Analysis. Energy 2019, 175, 195-204. [CrossRef]

39. Carbon Trading Network. Reference for $\mathrm{CO}_{2}$ Emission Coefficients of Energy Sources. Available online: http://www.tanjiaoyi com/article-3075-1.html (accessed on 9 May 2021).

40. China's Guidelines for the Preparation of Provincial Greenhouse Gas Inventories; The National Development and Reform Commission (NDRC) of the People's Republic of China: Beijing, China, 2011; Available online: https:/ /wenku.baidu.com/view/7ae95325f111 f18583d05a67.html (accessed on 11 May 2021).

41. Weltevreden, J.W.J.; Rietbergen, T.V. E-Shopping Versus City Centre Shopping: The Role of Perceived City Centre Attractiveness. Tijdschr. Voor Econ. Soc. Geogr. 2007, 98, 68-85. [CrossRef]

42. Rosqvist, L.S.; Hiselius, L.W. E-shOnline Shopping Habits and the Potential for Reductions in Carbon Dioxide Emissions from Passenger Transport. J. Clean. Prod. 2016, 131, 163-169. [CrossRef]

43. Wei, J.; Chen, H.; Long, R.Y.; Zhao, F. Application of the Capability Maturity Model to Evaluating the Carbon Capability Maturity of Urban Residents in 10 Eastern Provinces of China. Resour. Conserv. Recycl. 2019, 148, 11-22. [CrossRef]

44. Pata, U.K. Renewable Energy Consumption, Urbanization, Financial Development, Income and $\mathrm{CO}_{2}$ Emissions in Turkey: Testing EKC Hypothesis with Structural Breaks. J. Clean. Prod. 2018, 187, 770-779. [CrossRef]

45. Salman, M.; Long, X.L.; Dauda, L.; Mensah, C.N.; Muhammad, S. Different Impacts of Export and Import on Carbon Emissions Across 7 ASEAN Countries: A Panel Quantile Regression Approach. Sci. Total Environ. 2019, 686, 1019-1029. [CrossRef]

46. Gorus, M.S.; Aydin, M. The Relationship Between Energy Consumption, Economic Growth, and $\mathrm{CO}_{2}$ Emission in $\mathrm{MENA}$ Countries: Causality Analysis in the Frequency Domain. Energy 2019, 168, 815-822. [CrossRef]

47. Riti, J.S.; Song, D.Y.; Shu, Y.; Kamah, M. Decoupling $\mathrm{CO}_{2}$ Emission and Economic Growth in China: Is There Consistency in Estimation Results in Analyzing Environmental Kuznets Curve? J. Clean. Prod. 2017, 166, 1448-1461. [CrossRef]

48. Jiao, Z.L. Development of E-Commerce Logistics in China. In Contemporary Logistics in China; Liu, B.L., Lee, S.J., Wang, L., Li, X., Xiao, J.H., Eds.; Current Chinese Economic Report Series; Springer: Berlin/Heidelberg, Germany, 2014; pp. 127-141. [CrossRef]

49. Zhang, C.G.; Nian, J. Panel Estimation for Transport Sector $\mathrm{CO}_{2}$ Emissions and Its Affecting Factors: A Regional Analysis in China. Energy Policy 2013, 63, 918-926. [CrossRef]

50. Chen, B.K.; Zhang, C.C. Human Capital and Housing Prices in Chinese Cities. Soc. Sci. China 2016, 5, 43-64.

51. Shen, N.; Zhao, Y.Q.; Wang, Q.W. Diversified Agglomeration, Specialized Agglomeration, and Emission Reduction Effect-A Nonlinear Test Based on Chinese City Data. Sustainability 2018, 10, 2002. [CrossRef]

52. Dong, F.; Li, J.Y.; Wang, Y.; Zhang, X.Y.; Zhang, S.N.; Zhang, S.Q. Drivers of the Decoupling Indicator Between the Economic Growth and Energy-Related $\mathrm{CO}_{2}$ in China: A Revisit from the Per-Spectives of Decomposition and Spatiotemporal Heterogeneity. Sci. Total Environ. 2019, 685, 631-658. [CrossRef]

53. Raza, M.Y.; Lin, B.Q. Decoupling and Mitigation Potential Analysis of $\mathrm{CO}_{2}$ Emissions from Pakistan's Transport Sector. Sci. Total Environ. 2020, 730. [CrossRef] 
54. Wu, Y.; Tam, V.W.Y.; Shuai, C.Y.; Shen, L.Y.; Zhang, Y.; Liao, S.J. Decoupling China's Economic Growth from Carbon Emissions: Empirical Studies From 30 Chinese Provinces (2001-2015). Sci. Total Environ. 2019, 656, 576-588. [CrossRef] [PubMed]

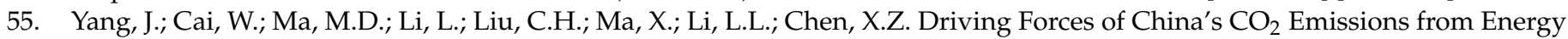
Consumption Based on Kaya-LMDI Methods. Sci. Total Environ. 2020, 711. [CrossRef] [PubMed]

56. Li, K.M.; Fang, L.T.; He, L.R. The Impact of Energy Price on $\mathrm{CO}_{2}$ Emissions in China: A Spatial Econometric Analysis. Sci. Total Environ. 2020, 706, 135942. [CrossRef]

57. Doolin, B.; Dillon, S.; Thompson, F.; Corner, J.L. Perceived Risk, the Internet Shopping Experience and Online Purchasing Behavior: A New Zealand Perspective. J. Glob. Inf. Manag. 2005, 13, 66-88. [CrossRef]

58. Zhang, G.X.; Deng, N.N.; Mou, H.Z.; Zhang, Z.G.; Chen, X.F. The Impact of the Policy and Behavior of Public Participation on Environmental Governance Performance: Empirical Analysis Based on Provincial Panel Data in China. Energy Policy 2019, 129, 1347-1354. [CrossRef]

59. Yang, W.Y.; Li, T.; Cao, X.C. Examining the Impacts of Socio-Economic Factors, Urban Form and Transportation Development on $\mathrm{CO}_{2}$ Emissions from Trans-Portation in China: A Panel Data Analysis of China's Provinces. Habitat Int. 2015, 49, 212-220. [CrossRef]

60. Chen, Y.M.; Li, X.; Zheng, Y.; Guan, Y.Y.; Liu, X.P. Estimating the Relationship Between Urban Forms and Energy Consumption: A Case Study in the Pearl River Delta, 2005-2008. Landsc. Urban Plan. 2011, 102, 33-42. [CrossRef]

61. Chen, D.K.; Chen, S.Y.; Jin, H. Industrial Agglomeration and $\mathrm{CO}_{2}$ Emissions: Evidence From 187 Chinese Prefecture-Level Cities Over 2005-2013. J. Clean. Prod. 2018, 172, 993-1003. [CrossRef]

62. Liu, X.C.; Sweeney, J. Modelling the Impact of Urban Form on Household Energy Demand and Related $\mathrm{CO}_{2}$ Emissions in the Greater Dublin Region. Energy Policy 2012, 46, 359-369. [CrossRef]

63. Miao, L. Examining the Impact Factors of Urban Residential Energy Consumption and $\mathrm{CO}_{2}$ Emissions in China-Evidence from City-Level Data. Ecol. Indic. 2017, 73, 29-37. [CrossRef]

64. Lu, I.J.; Lin, S.J.; Lewis, C. Decomposition and Decoupling Effects of Carbon Dioxide Emission from Highway Transportation in Taiwan, Germany, Japan and South Korea. Energy Policy 2007, 35, 3226-3235. [CrossRef]

65. The Third National People's Congress Standing Committee (NPC Standing Committee). Resolution of the Fifteenth Session of the Third National People's Congress Standing Committee of the People's Republic of China. Available online: www.npc.gov.cn/ wxzl/gongbao/2000-12/11/content_5000984.htm (accessed on 15 March 2021).

66. The Eighth National People's Congress (NPC). Decision of The Fifth Session of the Eighth National People's Congress of the People's Republic of China on Approving the Establishment of Chongqing Municipality Directly under the Central Government. Available online: www.npc.gov.cn/wxzl/gongbao/2001-02/06/content_5004679.htm (accessed on 15 March 2021).

67. Circular of State Council on the Several Policies and Measures for the Implementation of the Western Region Development; The State Council of the People's Republic of China: Beijing, China, 2000; Available online: http://www.gov.cn/gongbao/content/2001 / content_60854.htm (accessed on 3 May 2021).

68. Zhou, Z.B.; Liu, C.J.; Zeng, X.M.; Jiang, Y.; Liu, W.B. Carbon Emission Performance Evaluation and Allocation in Chinese Cities. J. Clean. Prod. 2018, 172, 1254-1272. [CrossRef]

69. Lan, C. Analysis of Cross-Sectional Data and Panel Data with Application of STATA; Wuhan University Press: Wuhan, China, 2012.

70. Pang, H. Econometrics; Science Press: Beijing, China, 2010.

71. Li, Z.; Ye, A. Advanced Applied Econometrics; Tsinghua University Press: Beijing, China, 2012.

72. Huge Engine-Automobile Data Strategy Institute, China Automobile Dealers Association. 2019 China Auto Consumption Trend Report. Available online: baijiahao.baidu.com/s?id=1651814311712997403\&wfr=spider\&for=pc (accessed on 25 March 2021).

73. Liu, B.Q.; Su, X.L.; Shi, J.X.; Hou, R. Does Urbanization Drive Economic Growth Decoupled from Energy Consumption in China's Logistics? J. Clean. Prod. 2020, 257, 120468. [CrossRef]

74. Baltagi, B.H. Econometric Analysis of Panel Data; John Wiley \& Sons: Hoboken, NJ, USA, 2005. 